\title{
The Effect of Alginate in Gastroesophageal Reflux in Infants
}

\author{
Silvia Salvatore ${ }^{1} \cdot$ Antonio Ripepi $^{1} \cdot$ Koen Huysentruyt $^{3} \cdot$ Kristel van de Maele $^{3} \cdot$ Luana Nosetti $^{1} \cdot$ Massimo Agosti $^{2}$. \\ Alessandro Salvatoni ${ }^{1} \cdot$ Yvan Vandenplas $^{3}$ (1)
}

Published online: 4 September 2018

(c) The Author(s) 2018

\begin{abstract}
Background Guidelines are contradictory regarding the use of alginate in infants with persisting gastroesophageal reflux (GER). While The British National Institute for Health and Care (NICE) guidelines consider alginate as a treatment option, the guidelines of the European and North-American Societies for Pediatric Gastroenterology, Hepatology and Nutrition (ESPGHAN, NASPGHAN) do not recommend alginates.

Aims We assessed the efficacy of alginate to reduce GER episodes in infants.

Methods In a prospective, observational study, we consecutively enrolled all infants referred for pH-multiple intraluminal impedance (pH-MII) recording because of persisting GER symptoms not responsive to behavior and dietetic modifications. A 48-h pH-MII was performed in all infants; a baseline recording was performed during the first $24 \mathrm{~h}$ while magnesium or sodium alginate was administered during the second $24 \mathrm{~h}$. The primary endpoint was the difference in the total number of GER episodes per $24 \mathrm{~h}$ between the baseline day and the second day during which the alginate was administered. The secondary outcome was the difference in symptoms between each period. We also compared other pH-MII data from before and during alginate administration.

Results We recruited 43 infants (median age 68 days, range 25-306); three pH-MII tracings were excluded because of artifacts. The median number of all MII reflux episodes was significantly reduced during alginate administration (76.0 vs 69.5; $p<0.001)$. Crying-fussiness, cough and regurgitation episodes all significantly improved during alginate administration ( $p=0.00012 ; p=0.005$ and $p=0.04$, respectively). The following MII parameters also decreased during the alginate administration: acid (19.0 vs $14.5 ; p<0.04)$, non-acid (52.0 vs $49.5 ; p<0.004)$, proximal GER episodes ( 46.0 vs $41.4 ; p<0.007)$, and bolus exposure index ( 1.9 vs $1.6 ; p=0.002)$. At least three out of seven $\mathrm{pH}-\mathrm{MII}$ parameters decreased by $>10 \%$ during the alginate period in 31/40 infants (77.5\%), without a significant difference between magnesium and sodium alginate.

Conclusion These results suggest that alginate significantly decreases the number and extension of both acid and non-acid reflux episodes and associated symptoms in infants.
\end{abstract}

\section{Key Points}

This study suggests that alginate may reduce gastroesophageal reflux (GER)-related symptoms in infants

Electronic supplementary material The online version of this article (https://doi.org/10.1007/s40272-018-0314-0) contains supplementary material, which is available to authorized users.

Yvan Vandenplas

yvan.vandenplas@uzbrussel.be

1 Division of Pediatrics, "F. Del Ponte" Hospital, University of Insubria, Varese, Italy

2 Division of Neonatology and Neonatal Intensive Care Unit, "F. Del Ponte" Hospital, Varese, Italy

3 Kidz Health Castle, UZ Brussel, Vrije Universiteit Brussel, Laarbeeklaan, 101, 1090 Brussels, Belgium and may decrease acid and non-acid GER episodes measured with $\mathrm{pH}$-impedance recording. However, a placebo-controlled, double-blind, randomized, controlled trial is needed to confirm these findings.

Alginate is a treatment option for GER-related symptoms in infants. 


\section{Introduction}

The diagnosis and management of gastro-esophageal reflux (disease) [(GERD)] in infants is challenging, mainly because of the lack of specificity of symptoms, the lack of an accurate diagnostic tool, and the lack of effective medication [1]. Regarding diagnostic investigations, normal ranges cannot be established as it is not ethical to perform investigations in healthy children. Regarding management, there is evidence that thickening of formula does reduce regurgitation and that proton pump inhibitors (PPIs) are effective in the management of peptic esophagitis [1]. However, there is no evidence regarding efficacy of any other intervention in troublesome GER and GERD in infants [1]. The North American and European Societies of Pediatric Gastroenterology, Hepatology and Nutrition (NASPGHAN, ESPGHAN) considered the evidence regarding the efficacy of alginate during infancy insufficient for alginate to be recommended in the guidelines published in 2018 [1]. However, a Cochrane review on the management of GERD in children concluded in 2014 that there was moderate evidence supporting the use of alginate, but the authors recommended further studies [2]. Moreover, the British National Institute for Health and Care Excellence (NICE) guidelines consider alginate as an appropriate treatment option in infants with frequent regurgitation and signs of distress or irritability not improving with dietary management [3].

Alginate is a polysaccharide derived from brown seaweed. Alginate-based formulations act on GER via chemical and physical mechanisms. Sodium and magnesium alginates are, respectively, the sodium and the magnesium salts of alginic acid, an anionic polysaccharide formed by blocks of (1-4)-linked $\beta$-D-mannuronate and its C-5 epimer $\alpha-\mathrm{L}-$ guluronate [4]. All alginate-based raft-forming formulations act via a unique mechanism, which differs from that of traditional antacids. In the presence of gastric acid, alginates precipitate, form a gel, and the bicarbonate (which is a possible additional component of alginate formulations) is converted to carbon dioxide, which becomes entrapped within the gel precipitate, converting it into a foam, which floats on the surface of the gastric contents $[5,6]$. The strength of the alginate raft is dependent on several factors, including the presence of aluminum or calcium and the amount of carbon dioxide. It is recommended to use formulations without aluminum and to consider the sodium content (variable according to the different commercial products) for prolonged use, particularly in preterm newborns and in children with kidney disease $[1,3]$. Alginate formulations require three chemical reactions to take place simultaneously: transformation to alginic acid, sodium carbonate reacting to form carbon dioxide, and calcium releasing free calcium ions to bind with alginic acid providing strength to raft formation [7].
The aim of our study was to assess the efficacy of alginate in infants with persisting symptoms of GER, despite appropriate behavioral and nutritional management as recommended by NASPGHAN and ESPGHAN [1].

\section{Materials and Methods}

\subsection{Study Population}

We consecutively enrolled all infants, 0-12 months old, referred between January 2016 and December 2016 for a $\mathrm{pH}$ and multiple intraluminal impedance ( $\mathrm{pH}-\mathrm{MII})$ recording because of persisting symptoms of GER. Infants were eligible for inclusion if they had (1) symptoms such as regurgitation and/or vomiting with additional prolonged episodes of inconsolable crying, fussiness, irritability, sleeping difficulties, or respiratory problems for at least 2 weeks, in the absence of any other identifiable cause, and if (2) there was no or insufficient response after at least 1 week of reassurance, behavior management, appropriate food intake (in terms of volume and frequency of meals), and dietary treatment [1].

Parental consent was obtained to prolong the planned $\mathrm{pH}-$ MII recording from 24 up to $48 \mathrm{~h}$, if the infant tolerated the $\mathrm{pH}-\mathrm{MII}$ well during the first $24 \mathrm{~h}$. Alginate was administered during the second period of $24 \mathrm{~h}$.

Exclusion criteria were patients older than 1 year of age; treatment with a PPI, H2-receptor blockers or other drugs affecting gastrointestinal motility or GER in the last week; gastrointestinal surgery or malformation or neurological diseases; and parental or patient non-compliance with the study design. It was decided also a priori that if a $\mathrm{pH}-\mathrm{MII}$ lasted $<38 \mathrm{~h}$ and/or had multiple, prolonged (representing $>10 \%$ of the total tracing) artifacts when analyzed, the tracing was discarded for analysis.

\subsection{Study Design}

This was a prospective, pharmacological, observational case-control study performed in two centers. Each patient served as his own control. The STROBE checklist for observational studies was followed. All infants fulfilling the inclusion criteria underwent a 48-h GER pH-MII; parameters and symptoms were assessed and compared between the baseline 24-h pH-MII and the second $24 \mathrm{~h}$, during which alginate was administered. The investigator analyzing the $\mathrm{pH}-\mathrm{MII}$ and the symptoms was blinded for the time period during which the data was collected.

The primary endpoint was the total number of GER episodes over $24 \mathrm{~h}$ recorded by impedance during baseline and during alginate administration. Other pH-MII data [number of acid and non-acid GER episodes, proximal GER episodes, 
bolus exposure index, duration of the reflux episode, reflux index (RI, \% of time with a $\mathrm{pH}<4.0)]$ were assessed and compared as well. Proximal GER was defined when GER reached the proximal two MII channels [8]. The time needed for acid and for a bolus GER to be cleared from the esophagus was defined as mean acid clearance time and mean bolus clearance time, respectively. The secondary endpoint was the incidence of symptoms reported during baseline $\mathrm{pH}-\mathrm{MII}$ and during alginate administration.

Details on the pH-MII technique can be found in the additional information available online (see electronic supplementary material). After downloading the data, the pH-MII tracings were divided into two periods, before and during alginate administration, of similar duration (19-24 h). Data were analyzed using specific software (BioVIEW Analysis Sandhill Scientific, version 5.0.9) and then manually inspected by one expert investigator (SS), who was blinded for the drug administration. Artifacts were considered when a square area or a fixed impedance horizontal line or rapid repeated vertical lines were present. We decided arbitrarily to discard tracings if the artifacts accounted for $>10 \%$ of the registration period, while if the artifacts were $<10 \%$, the tracing was included in the study but the period of artifacts and/or the specific channel were excluded from the analysis.

The RI was considered pathologic if $\geq 7 \%$, as indicated by ESPGHAN guidelines [9]. The presence of $>100$ MII GER episodes in $24 \mathrm{~h}$ was considered pathologic [10,11].

We compared baseline pH-MII GER results with the second $24 \mathrm{~h}$ comprising alginate administration for the primary and secondary outcomes, as well as for the other impedance parameters. The median difference for each parameter between the two 24-h periods was also calculated, as this parameter provides information on the importance of change.

We attempted also to provide information on the number of patients with improved, unchanged or worsened $\mathrm{pH}-\mathrm{MII}$ parameters and symptoms during alginate administration. Therefore, we arbitrarily accepted a small change of up to $10 \%$ in any of the parameters as an unchanged result related to normal day-by-day variability, as a previous study performed in 10 children showed that the number of bolus GER episodes did not differ from day to day during a 48-h recording [12]. Consequently, improvement and worsening would refer to a variation of at least $10 \%$ as a decrease or an increase, respectively, between the two 24-h periods.

As a change in one single parameter might be insufficient to suggest efficacy and/or not be clinically relevant, we arbitrarily defined an 'improvement' as a reduction of $>10 \%$ in three or more of the following seven principal pH-MII parameters: total number of refluxes, number of acid refluxes, number of non-acid refluxes, proximal refluxes, RI, and percentage of acid and non-acid exposure time. We also calculated the number and percentage of patients with a decrease of at least $20 \%$ for three of the above pH-MII parameters.

\subsection{Symptom Association}

Symptom association was based on two classic parameters: symptom index (SI) and symptom association probability (SAP) $[13,14]$. SI represents the number of GER-related symptoms on the total number of symptoms, and is defined as pathological when $\geq 50 \%$. The SAP is the likelihood that the patient's symptoms were related to reflux, calculated by analyzing consecutive 2-min segments [15] and based on a Fisher's table of contingency, and is considered pathologic when $\geq 95 \%$. We considered the total number of symptoms associated in time with a GER episode occurring during baseline recording and during alginate administration. Information on the SI and SAP is also provided.

\subsection{Diary}

At enrolment, we educated parents about the importance of precise reporting of symptoms during the entire (day and night) $\mathrm{pH}-\mathrm{MII}$ registration using the internal clock of the device. Parents were also asked to ensure that the second day was as similar as possible to the baseline day for sleeping and mealtimes, feeding type and volume, position, and other day and night activities, and to record any change. We gave each parent a routine-use diary to record infant mealtimes and sleeping times or wakefulness phases, and symptoms such as crying, fussiness, cough, vomiting, and regurgitation. All infants participating in this study were hospitalized. At the end of the investigation, all symptoms and events were registered in the software for analysis.

\subsection{Alginate Formulations}

Two alginate formulations, sodium and magnesium alginate, previously reported in infant studies were tested according to the age of infants and availability in the department [16, 17] (see Table 1 for composition of the alginates).

The dosage used was $1 \mathrm{~mL} / \mathrm{kg} /$ day divided over the number of meals for both formulations, administered after each feeding during the second 24-h period of pH-MII recording $[1,17]$.

\subsection{Statistical Analysis}

The sample size was calculated at a 2-tailed significance level of $5 \%$ and with a power of $85 \%$ with a level of significance fixed at $p<0.05$ (performed on $\mathrm{G}^{*}$ Power 3.1.9.2 for Windows) and resulted in the inclusion of 40 infants.

The intention-to-treat analysis was performed using www.socscistatistics.com and www.statpages.info and 
Table 1 Composition of both alginates

\begin{tabular}{|c|c|c|}
\hline Alginate & Brand name (manufacturer) & Ingredients \\
\hline Sodium alginate & Gaviscon ${ }^{\circledR}$ (Reckitt Benckiser Healthcare, Hull, UK) & $\begin{array}{l}\text { Sodium alginate } 500 \mathrm{mg} \text {, sodium bicarbonate } \\
267 \mathrm{mg} \text {, methyl parahydroxybenzoate (E218) } \\
40 \mathrm{mg} \text {, propyl parahydroxybenzoate (E216) } \\
6 \mathrm{mg} \text {, calcium carbonate, carbomers, sodium } \\
\text { saccharin, flavour fennel, sodium hydroxide, } \\
\text { erythrosine, purified water }\end{array}$ \\
\hline Magnesium alginate & $\begin{array}{l}\text { Gastrotuss baby }{ }^{\circledR} \text { (Drugs Minerals and Generics Italia S.r.l., } \\
\text { Pomezia, Roma, Italy) }\end{array}$ & $\begin{array}{l}\text { Magnesium alginate, simethicone, fructose, } \\
\text { xanthan gum, d-panthenol, sodium bicarbo- } \\
\text { nate, sodium hydroxide, methyl p-hydroxy- } \\
\text { benzoate, propyl p-hydroxybenzoate, natural } \\
\text { flavours, purified water }\end{array}$ \\
\hline
\end{tabular}

using Microsoft Excel files. Differences in GER parameters and symptoms between the two 24 -h periods were tested with the Wilcoxon-signed rank test and expressed as median of each difference (specifying the $25-75 \%$ interval). Percentages were used to interpret general and specific improvements with $95 \%$ confidence intervals (95\% CI). Chi square statistics (with a significance level of $95 \%$ ) were used to compare the two different treatments (sodium vs magnesium alginate).

\subsection{Ethical Committee and Informed Consent}

The study protocol was approved by the Ethical Committee of the two hospitals. Written informed parental consent was obtained before each examination. Parents participating in the study approved the extension of the $\mathrm{pH}-\mathrm{MII}$ recording, if well tolerated, up to $48 \mathrm{~h}$ to test the effect of alginate administration.

\section{Results}

A 48-h pH-MII was performed in 43 infants fulfilling the inclusion criteria. All infants tolerated the pH-MII very well. After downloading the recording, three $\mathrm{pH}-\mathrm{MII}$ tracings were excluded because of prolonged artifacts. Data from 40 infants [ 20 boys, 20 girls; median age 68 days (range 25-306); median weight $4455 \mathrm{~g}$ (range 3145-8500 g)] were available for analysis. Two patients developed symptoms of an acute infectious disease, diarrhea and fever, during the recording. These were not excluded from the analysis to avoid any selective bias. The alginate administered was Gaviscon ${ }^{\circledR}$ in 17 and Gastrotuss ${ }^{\circledR}$ in 23 infants. Regarding the primary outcome, the median number of total GER episodes measured by impedance was significantly reduced during alginate administration (baseline vs alginate: 76.0 vs 69.5; $p<0.001$ ) (Table 2; Fig. 1).

The pH-MII was pathologic (RI $>7 \%$; total GER episodes $>100)$ in 14 patients (35\%): the RI was abnormal $(>7 \%)$ in $8 / 40(20 \%)$ infants and the total number of GER episodes measured with MII ( $>100$ episodes) was increased in in $9 / 40$ patients $(22.5 \%)$; both parameters were abnormal

Table 2 pH-multiple intraluminal impedance (pH-MII) data considering the seven main gastroesophageal (GER) parameters

\begin{tabular}{|c|c|c|c|c|c|c|c|c|c|c|}
\hline \multirow[t]{2}{*}{ Parameter } & \multicolumn{2}{|l|}{ Total } & \multicolumn{2}{|c|}{ Median } & \multirow[t]{2}{*}{ Med dif } & \multirow[t]{2}{*}{$p$ value (2-tailed) } & \multicolumn{2}{|c|}{ Improvement } & \multicolumn{2}{|c|}{ No. pt improved } \\
\hline & Base & Alg & Base & Alg & & & Min & Max & $>10 \%$ & $>20 \%$ \\
\hline Tot-GER & 3114 & 2677 & 76 & 69.5 & -8.5 & $<0.001$ & -1 & -62 & 19 & 14 \\
\hline Ac-GER & 793 & 660 & 19 & 14.5 & -3.5 & 0.04 & -2 & -23 & 24 & 22 \\
\hline NAc-GER & 2312 & 1968 & 52 & 49.5 & -8.5 & $<0.01$ & -3 & -59 & 22 & 19 \\
\hline Prox-GER & 1964 & 1730 & 46 & 41.5 & -5.0 & 0.006 & -2 & -43 & 21 & 14 \\
\hline BEI $(\%)$ & 62 & 49 & 1.9 & 1.6 & -0.3 & 0.002 & -0.2 & -3.1 & 28 & 20 \\
\hline Ac BEI (\%) & 17 & 14 & 0.5 & 0.3 & -0.1 & 0.167 & -0.1 & -1.2 & 18 & 14 \\
\hline $\mathrm{RI}(\%)$ & 152 & 125 & 2.7 & 2.2 & -0.3 & 0.25 & -0.2 & -11.2 & 19 & 17 \\
\hline
\end{tabular}

Ac acid, Ac-GER acid GER episodes, Alg alginate administration, Base baseline recording, BEI bolus exposure index, Med dif median difference, NAc-GER non-acid GER episodes, Prox-GER proximal GER episodes, Pt patients, $R I$ reflux index $(\%$ of time pH $<4.0)$, Tot-GER total GER episodes 


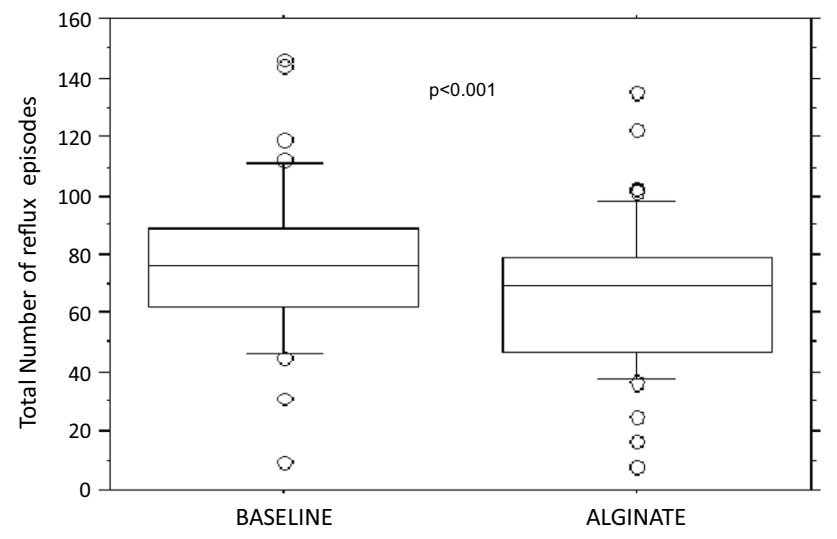

Fig. 1 Total number of reflux episodes at baseline and during alginate administration. Box plot shows the number of reflux episodes detected by impedance (median, interquartiles). The number of reflux episodes was significantly decreased during alginate administration $(p<0.001)$

in $3 / 40(7.5 \%)$ infants. The SI and SAP were abnormal in $29 / 40(73 \%)$. In the infants with a pathologic pH-MII, we observed a similar rate of general improvement (defined as $\geq 10 \%$ in $\geq 3 / 7$ parameters) in $6 / 8(75 \%)$ of those with an elevated RI (CI 35-97\%), and in 7/9 (77\%) of those with more than 100 GER episodes on MII (CI 40-97\%). Detailed information on the difference between baseline and alginate administration in the subgroup of infants with a pathological $\mathrm{pH}-\mathrm{MII}$ (an RI of $>7 \%$, or $>100$ reflux episodes) is provided in Table 3. The median improvement in RI on Day 2 compared with Day 1 was $-3.0 \%$ [interquartile range (IQR) -7.15 to 3.25], and the number of reflux episodes observed with MII decreased with a median of -16 (IQR -27 to - 2). In those patients with pathologic $\mathrm{pH}-\mathrm{MII}$ symptom association (pathologic SI and/or SAP), 72\% (CI 53-87\%) had an improvement with $>10 \%$ in $3 / 7$ parameters and $69 \%$ (CI $49-85 \%$ ) with $>20 \%$.
The number of acid (19 vs 14.5; $p<0.04$ ), non-acid (52 vs 49.5; $p<0.004$ ), and proximal GER (46 vs 41.5; $p<0.007$ ) episodes, and the bolus exposure index (1.9 vs $1.6 \%$; $p=0.002$ ), were all significantly reduced during alginate administration (Table 2). There was a non-significant effect on the RI ( $p=0.25)$, the duration of the longest reflux episode $(p=0.12)$ and of the longest acid GER $(p=0.13)$, and the duration of the acid bolus exposure index $(p=0.17)$, of the mean acid clearance time $(p=0.16)$, and of the median bolus clearance time $(p=0.16)$ (Table 2$)$.

A decrease of at least $10 \%$ in three or more $\mathrm{pH}-\mathrm{MII}$ parameters during the alginate period was observed in 31/40 infants (77.5\% ; 95\% CI 62-89). There was an improvement of all seven parameters in five infants; of six of the parameters in four patients, of five in eight patients, of four in seven patients, and of three in the other seven patients. Conversely, during the alginate period, the total number of reflux episodes, the bolus exposure index, and the RI worsened in 5, 6, and 13 infants, respectively. Two of these infants had acute enteritis and fever during the investigation. When considering a reduction of at least $20 \%$ in three or more of the seven pH-MII parameters, $27 / 40(67.5 \%, 95 \%$ CI 51-81) of the tracings showed improvement (Table 2).

The number of proximal GER episodes during baseline compared with the alginate period are shown in online supplementary Fig. 1. Of the 29 patients with a pathologic SI and/or SAP, there was a similar rate of improvement in at least three GER parameters during the alginate administration in $21(72 \%)(95 \%$ CI 53-87) and in 20 (69\%) (95\% CI 49-85) infants, considering the threshold of $10 \%$ or $20 \%$, respectively.

The secondary outcome was the evolution of regurgitation and other reflux-related symptoms during alginate administration compared with baseline (Table 4, Fig. 2). All 40 infants presented episodes of crying or fussiness (37 crying and 24 fussiness) and because parents often reported these

Table 3 pH-multiple intraluminal impedance (pH-MII) parameters at baseline and during alginate administration in the subgroup with an abnormal reflux index $(>7 \%)$ or number of reflux episodes $(>100)$

\begin{tabular}{|c|c|c|c|c|c|}
\hline & $\begin{array}{l}\text { Baseline (no. of } \\
\text { patients) }\end{array}$ & $\begin{array}{l}\% \text { change in } \geq 3 \text { of } 7 \\
\text { parameters }\end{array}$ & $\begin{array}{l}\text { Alginate (no. of } \\
\text { patients) }\end{array}$ & $\%$ Improved & $95 \% \mathrm{CI}$ \\
\hline \multirow[t]{2}{*}{$\mathrm{RI}>7 \%$} & 8 & $>10$ & 6 & 75 & $35-97$ \\
\hline & 8 & $>20$ & 4 & 50 & $16-84$ \\
\hline \multirow[t]{2}{*}{ GER ep $>100$} & 9 & $>10$ & 7 & 77 & $40-97$ \\
\hline & 9 & $>20$ & 6 & 66 & $30-93$ \\
\hline \multirow[t]{2}{*}{$\mathrm{RI}>7 \%$ or GER ep $>100$} & 14 & $>10$ & 11 & 78 & $49-95$ \\
\hline & 14 & $>20$ & 9 & 64 & $35-87$ \\
\hline \multirow[t]{2}{*}{ Abnl SI or SAP } & 29 & $>10$ & 21 & 72 & $53-87$ \\
\hline & 29 & $>20$ & 20 & 69 & $49-85$ \\
\hline
\end{tabular}

Abnl SI or SAP abnormal symptom index or symptom association probability, CI confidence interval, GER ep gastroesophageal reflux episodes, $R I$ reflux index 
Table 4 Symptoms reported during $\mathrm{pH}$-multiple intraluminal impedance (pH-MII)

\begin{tabular}{lllll}
\hline Symptom & \multicolumn{2}{l}{ Total number of episodes } & & \\
\cline { 2 - 4 } & At baseline & $\begin{array}{l}\text { During } \\
\text { alginate } \\
\text { treatment }\end{array}$ & $\begin{array}{l}\text { Median- } \\
\text { differ- } \\
\text { ence }\end{array}$ & $p$ value \\
\hline $\begin{array}{c}\text { Crying/Fussiness } \\
(n=40)\end{array}$ & 646 & 457 & -3.5 & 0.00012 \\
$\begin{array}{c}\text { Regurgitation } \\
(n=33)\end{array}$ & 176 & 107 & -1 & 0.042 \\
\begin{tabular}{c} 
Cough $(n=32)$ \\
\hline
\end{tabular} & 352 & 234 & -1 & 0.005 \\
\hline
\end{tabular}
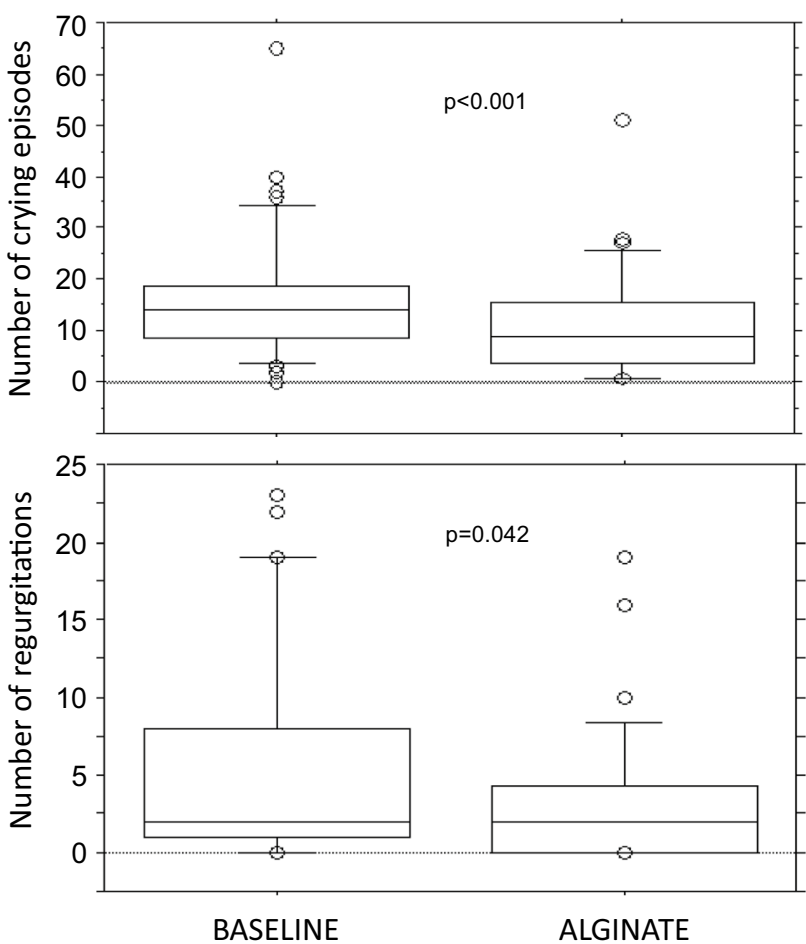

Fig. 2 Symptoms at baseline and during alginate administration. Upper panel, box plot showing the number of episodes of crying (median, interquartiles); lower panel, box plot showing the number of episodes of regurgitation (median, interquartiles). The number of episodes of crying and regurgitation were significantly decreased during alginate administration ( $p<0.001$ and $p=0.042$, respectively)

symptoms simultaneously, expressing difficulties in separating them, we grouped them for further analysis (Table 4). Crying/fussiness, cough, and regurgitation episodes all significantly improved during alginate administration ( $p=0.00012 ; p=0.005$; and $p=0.042$, respectively). When we considered only the infants with a minimum of three episodes (for each symptom) during the investigation, 26/36 (72\%) with crying/fussiness, 10/13 (77\%) with regurgitation, and 15/20 (75\%) with cough showed an improvement of symptoms during alginate administration, with a mean reduction of 7, 7.6, and 8.8 episodes per day, respectively. The reduction in the episodes of symptoms was $>20 \%$ in $23 / 36(64 \%)$ for crying/fussiness, in $9 / 13$ (69\%) for regurgitation, and in 13/20 (65\%) for cough, respectively (Table 4).

There was no difference in effect between the two alginate formulations: an improvement of at least $10 \%$ in three or more GER parameters was observed in $74 \%$ (17/23 patients; 95\% CI 52-90) of the patients treated with magnesium alginate and in 82\% (14/17 patients; 95\% CI 57-96) of those treated with sodium alginate (Chi square test: 0.399; $p=0.527)$.

\section{Discussion}

A significant decrease in the number of reflux episodes (primary endpoint) and of symptoms (secondary endpoint) was observed during alginate administration, assessed during a 48-h pH-MII. The feasibility and repeatability of 48-h pH-MII recording has been recently supported by two studies in infants $[12,18]$. One study aimed to optimize the reflux-symptom association statistics, the other evaluated the effect of a challenge in children with cow's milk allergy on GER episodes [12, 18].

The data on alginate in infants are limited. More than 20 years ago, sodium alginate was shown to significantly decrease the frequency and severity of vomiting in infants $[19,20]$. Recently, a reduction of a validated infant GER score, the Infant-GER-Questionnaire-Revised (I-GERQ-R), was reported in infants treated with a new alginate formulation with simethicone [16]. However, only three studies have assessed the effect of alginate on GER with pH-MII. Two studies were performed in preterm infants, and reported a significant decrease in the number of acid GER and proximal esophageal reflux episodes [17, 21]. In the study by Del Buono et al. of 20 infants, results showed a marginal but significant difference between Gaviscon Infant and placebo in average reflux height, and raised questions regarding any perceived clinical benefit of its use [22]. The median number of reflux events/hour (1.58 vs 1.68), acid reflux events/hour (0.26 vs 0.43$)$, minimum distal or proximal $\mathrm{pH}$, total acid clearance time per hour (time with $\mathrm{pH}$ below $\mathrm{pH} 4$ ), and total reflux duration per hour were not significantly different after alginate than after placebo [22]. Alginate creates a viscous gel or 'rafting' in the upper part of the stomach, acting rapidly, often within a few minutes of dosing and its presence and effect in the stomach persists for up to $4 \mathrm{~h}$ [23]. Since alginate formulation can persist in the stomach for up to $4 \mathrm{~h}$ after administration [18], we decided to perform a 48-h pH-MII to avoid the possible ongoing effect of alginate administered during a previous meal on the following drug-free meal. In the study by Del Buono et al. [22], meals 
without and with alginate were altereds, possibly inducing a still ongoing effect of alginate during a drug-free meal. A similar design was used in the studies in preterm babies $[17,21]$. Our study design attempted to reduce these possibly confounding factors by comparing two subsequent consecutive 24-h periods, one for baseline and the second for alginate administration. Both 24-h registrations were as similar as possible regarding confounding variables such as feeding and awake/asleep periods. However, an adaptation of the infant to the presence of the probe during the second period of $24 \mathrm{~h}$ may have introduced a normalizing effect.

Theoretically, simethicone may also have a beneficial effect as it reduces the presence of gas in the stomach, favoring gastric emptying [24]. The number of all MII parameters, acid and non-acid reflux, proximal episodes, and bolus exposure index were significantly reduced during alginate administration. The number of episodes of crying or fussiness, regurgitation, and cough reported during alginate administration were also significantly reduced. Although all these changes were statistically highly significant, the clinical relevance of these differences remains to be ascertained based on the individual patient (and related parental concern) and follow-up. Besides, when acid is the predominant GER component and determinant of symptoms, alginate treatment could be suboptimal since the RI, acid bolus exposure index, and the mean acid clearance time were not significantly reduced.

In 2000, a review on the effect of alginate-based specific formulations (Gaviscon and Gaviscon Infant) included six pediatric studies, of which only one was a double-blind trial, including 303 children or infants. It showed an overall significant reduction of regurgitation/vomiting and heartburn, in combination with a possible benefit on the $\mathrm{pH}$-monitoring parameters, but concluded that the alginate-based formulations were less effective than $\mathrm{H} 2$-antagonists for the treatment of esophagitis [25]. Tolerance was satisfactory in all patients and the only report assessing side effects showed diarrhea or constipation in a few patients, with a similar rate compared with placebo. The heterogeneity in age of the populations, of commercial alginate formulations tested, and of outcomes considered did not allow a proper meta-analysis of the results [25]. A Cochrane review concluded in 2014 that their moderate evidence indicates that Gaviscon Infant ${ }^{\circledR}$ improves symptoms in infants, including those with functional reflux; the largest study of the current formulation showed improvement in symptom control [2]. No serious side effects were reported [2]. Accordingly, the NICE guidelines consider alginate both for bottle-fed and breast-fed infants with frequent regurgitation associated with marked distress that continues despite a step-care approach based on parental reassurance, postural treatment, nutritional assessment, and advice [3]. In adults, alginates have been shown to be more effective than placebo or antacids for treating GERD symptoms [26-28]. However, because of the limited evidence for efficacy of alginate in children, the NASPGHAN and ESPGHAN guidelines do not recommend its use [1]. Our data add arguments in favor to the Cochrane analysis and NICE guidelines.

Our study does have some limitations. The Ethical Committee refused a placebo arm in these symptomatic infants. We cannot exclude the possibility that the parents may have under-reported symptoms during the second 24-h intervention period. However, it is clinical practice to associate GER with symptoms based on a parental report. In order to reduce diary inaccuracy as much as possible, parents were informed before the investigation about the importance of the precise reporting of symptoms. The design of the study (24-h baseline recording followed by 24-h recording on alginate) may have introduced a bias towards a (false) beneficial effect of the alginate, as reflux parameters may decrease spontaneously during the second 24-h period of a 48-h recording. Regarding $\mathrm{pH}$ measurement, low and good reproducibility have been reported [29, 30]. However, according to a detailed analysis of a $48-\mathrm{h} \mathrm{pH}-\mathrm{MII}$ in ten infants, there was no difference observed between the two 24-h periods [12]. Zerbib et al. showed good reproducibility for the number, acidity and air-liquid composition of reflux episodes in healthy adults (Kendall's $W$ values $0.72-0.85$ ) [31].Visual reviewing of the $\mathrm{pH}-\mathrm{MII}$ tracing could introduce subjective selection of GER episodes and intra-observer variability. However, we believe that the combined use of the automatic software analysis (as a screen background) and the single expert investigator, who was blind to the intervention period during the analysis, limits this risk for interpretation bias. Two different alginate products were tested, Gastrotuss ${ }^{\circledR}$ in Italy and Gaviscon ${ }^{\circledR}$ in Belgium. Because this study was performed unsponsored, only products that were available in the hospital were used. However, given the small differences in composition between products, it is very unlikely that these would have had a different effect (a separate analysis comparing the efficacy of the two products did not reveal any difference-data not shown). The information provided is short term, for only the first $24 \mathrm{~h}$ of alginate administration. A placebo-controlled prospective trial evaluating the longterm efficacy of alginate on symptoms is recommended.

\section{Conclusion}

The number and proximal extension of both acid and nonacid reflux episodes and GER symptoms were significantly reduced during alginate administration when compared with baseline. A 48-h pH-MII was well tolerated by infants and well perceived by the parents, and could be introduced in compliant patients to further improve the diagnostic validity of the investigation and to test the efficacy of GER treatment. 
Author Contributions SS designed the study, collected the patients, analyzed and interpreted the data, and wrote and revised the manuscript; AR performed the investigations, analyzed the data, and wrote the manuscript; KH And KV collected the patients, performed the investigations, and revised and approved the manuscript; LN collected the patients, interpreted the data, and revised the manuscript; AS and MA supervised the study, interpreted the data, and revised the manuscript; YV designed and supervised the study, collected the patients, interpreted the data, and wrote and revised the manuscript. All authors read and approved the final version of the manuscript.

\section{Compliance with Ethical Standards}

Conflict of interest SS has participated as a consultant and/or speaker for Danone-Nutricia, Deca, IMS-Health, Menarini, and Nestle. YV has participated as a clinical investigator, and/or advisory board member, and/or consultant, and/or speaker for Abbott Nutrition, Biocodex, Danone, Nestle Health Science, Nestle Nutrition Institute, Nutricia, Mead Johnson, and United Pharmaceuticals. None of the above manufacturers and companies have had any input or involvement in any aspect of this study. The other authors have no conflicts of interest to disclose.

Funding No funding or other support was given for this study.

Open Access This article is distributed under the terms of the Creative Commons Attribution-NonCommercial 4.0 International License (http://creativecommons.org/licenses/by-nc/4.0/), which permits any noncommercial use, distribution, and reproduction in any medium, provided you give appropriate credit to the original author(s) and the source, provide a link to the Creative Commons license, and indicate if changes were made.

\section{References}

1. Rosen R, Vandenplas Y, Singendonk M, et al. Pediatric gastroesophageal reflux clinical practice guidelines: joint recommendations of the north american society for pediatric gastroenterology, hepatology, and nutrition and the European society for pediatric gastroenterology, hepatology, and nutrition. J Pediatr Gastroenterol Nutr. 2018;66(3):516-54.

2. Tighe M, Afzal NA, Bevan A, et al. Pharmacological treatment of children with gastro-oesophageal reflux. Cochrane Database Syst Rev. 2014;(11):CD008550. https://doi.org/10.1002/14651 858.CD008550.pub2.

3. National Institute for Health and Care Excellence (NICE). Gastrooesophageal reflux disease: recognition, diagnosis and management in children and young people. (Clinical Guideline 193) 2015. http://www.nice.org.uk/guidance/NG1.

4. Johnson FA, Craig DQ, Mercer AD. Characterization of the block structure and molecular weight of sodium alginates. J Pharm Pharmacol. 1997;49(7):639-43.

5. Lambert JR, Korman MG, Nicholson L, et al. In-vivo antireflux and raft properties of alginates. Aliment Pharmacol Ther. 1990;4(6):615-22.

6. Washington N, Greaves JL, Wilson CG. Effect of time of dosing relative to a meal on the raft formation of an anti-reflux agent. J Pharm Pharmacol. 1990;42(1):50-3.

7. Dettmar PW, Gil-Gonzalez D, Fisher J, et al. A comparative study on the raft chemical properties of various alginate antacid raftforming products. Drug Dev Ind Pharm. 2018;44(1):30-9.
8. Salvatore S, Arrigo S, Luini C, et al. Esophageal impedance in children: symptom-based results. J Pediatr. 2010;157(6):949-54. e1-2.

9. Vandenplas Y, Rudolph CD, Di Lorenzo C, et al. Pediatric gastroesophageal reflux clinical practice guidelines: joint recommendations of the North American society for pediatric gastroenterology, hepatology, and nutrition (NASPGHAN) and the European society for pediatric gastroenterology, hepatology, and nutrition (ESPGHAN). J Pediatr Gastroenterol Nutr. 2009;49(4):498-547.

10. Pilic D, Höfs C, Weitmann S, et al. Inter- and intraobserver agreement in 24-hour combined multiple intraluminal impedance and $\mathrm{pH}$ measurement in children. J Pediatr Gastroenterol Nutr. 2011;53(3):255-9.

11. Mousa H, Hassan M. Gastroesophageal reflux disease. Pediatr Clin North Am. 2017;64(3):487-505.

12. Omari TI, Schwarzer A, van Wijk MP, et al. Optimisation of the reflux-symptom association statistics for use in infants being investigated by 24-hour $\mathrm{pH}$ impedance. J Pediatr Gastroenterol Nutr. 2011;52(4):408-13.

13. Wiener GJ, Richter JE, Copper JB, et al. The symptom index: a clinically important parameter of ambulatory 24-hour esophageal pH monitoring. Am J Gastroenterol. 1988;83(4):358-61.

14. Breumelhof R, Smout AJ. The symptom sensitivity index: a valuable additional parameter in 24-hour esophageal $\mathrm{pH}$ recording. Am J Gastroenterol. 1991;86(2):160-4.

15. Lam HG, Breumelhof R, Roelofs JM, et al. What is the optimal time window in symptom analysis of 24-hour esophageal pressure and pH data? Dig Dis Sci. 1994;39(2):402-9.

16. Ummarino D, Miele E, Martinelli M, et al. Effect of magnesium alginate plus simethicone on gastroesophageal reflux in infants. J Pediatr Gastroenterol Nutr. 2015;60(2):230-5.

17. Corvaglia L, Aceti A, Mariani E, et al. The efficacy of sodium alginate (Gaviscon) for treatment of gastroesophageal reflux in preterm infants. Aliment Pharmacol Ther. 2011;33(4):466-70.

18. Borrelli O, Mancini V, Thapar N, et al. Cow's milk challenge increases weakly acidic reflux in children with cow's milk allergy and gastroesophageal reflux disease. J Pediatr 2012;161(3):47681.e1.

19. Buts JP, Barudi C, Otte JB. Double-blind controller study on the efficacy of sodium alginate (Gaviscon) in reducing gastroesophageal reflux assessed by $24 \mathrm{~h}$ continuous $\mathrm{pH}$ monitoring in infants and children. Eur J Pediatr. 1986;146(2):156-8.

20. Miller S. Comparison of the efficacy and safety of a new aluminum-free pediatric alginate preparation and placebo in infants with recurrent gastro-oesophageal reflux. Curr Med Res Opin. 1999;15(3):160-8.

21. Corvaglia L, Spizzichino M, Zama D, et al. Sodium Alginate (Gaviscon ${ }^{\circledR}$ ) does not reduce apnoeas related to gastro-oesophageal reflux in preterm infants. Early Hum Dev. 2011;87(12):775-8.

22. Del Buono R, Wenzl TG, Ball G, et al. Effect of Gaviscon Infant on gastro-oesophageal reflux in infants assessed by combined intraluminal impedance/pH. Arch Dis Child. 2005;90(5):460-3.

23. Johnson FA, Craig DQ, Mercer A, et al. The use of image analysis as a means of monitoring bubble formation in alginate rafts. Int $\mathbf{J}$ Pharmaceut. 1998;170:179-85.

24. Bertoni G, Gumina C, Conigliaro R, et al. Randomized placebocontrolled trial of oral liquid simethicone prior to upper gastrointestinal endoscopy. Endoscopy. 1992;24(4):268-70.

25. Mandel KG, Daggy BP, Brodie DA, et al. Review article: alginateraft formulations in the treatment of heartburn and acid reflux. Aliment Pharmacol Ther. 2000;14(6):669-90.

26. Leiman DA, Riff BP, Morgan S, et al. Alginate therapy is effective treatment for GERD symptoms: a systematic review and metaanalysis. Dis Esophagus. 2017;30(5):1-9.

27. Chiu CT, Hsu CM, Wang CC, et al. Randomised clinical trial: sodium alginate oral suspension is non-inferior to omeprazole in 
the treatment of patients with non-erosive gastroesophageal disease. Aliment Pharmacol Ther. 2013;38(9):1054-64.

28. De Ruigh A, Roman S, Chen J, et al. Gaviscon double action liquid (antacid \& alginate) is more effective than antacid in controlling post-prandial oesophageal acid exposure in GERD patients: a double-blind crossover study. Aliment Pharmacol Ther. 2014;40(5):531-7.

29. Nielsen RG, Kruse-Andersen S, Husby S. Low reproducibility of $2 \times 24$-hour continuous esophageal $\mathrm{pH}$ monitoring in infants and children: a limiting factor for interventional studies. Dig Dis Sci. 2003;48(8):1495-502.

30. Vandenplas Y, Helven R, Goyvaerts H, et al. Reproducibility of continuous 24 hour oesophageal $\mathrm{pH}$ monitoring in infants and children. Gut. 1990;31(4):374-7.

31. Zerbib F, des Varannes SB, Roman S, et al. Normal values and day-to-day variability of 24-h ambulatory oesophageal impedance-pH monitoring in a Belgian-French cohort of healthy subjects. Aliment Pharmacol Ther. 2005;22(10):1011-21. 